\title{
THE MAGSORB PROCESS FOR BULK SEPARATION OF CARBON DIOXIDE
}

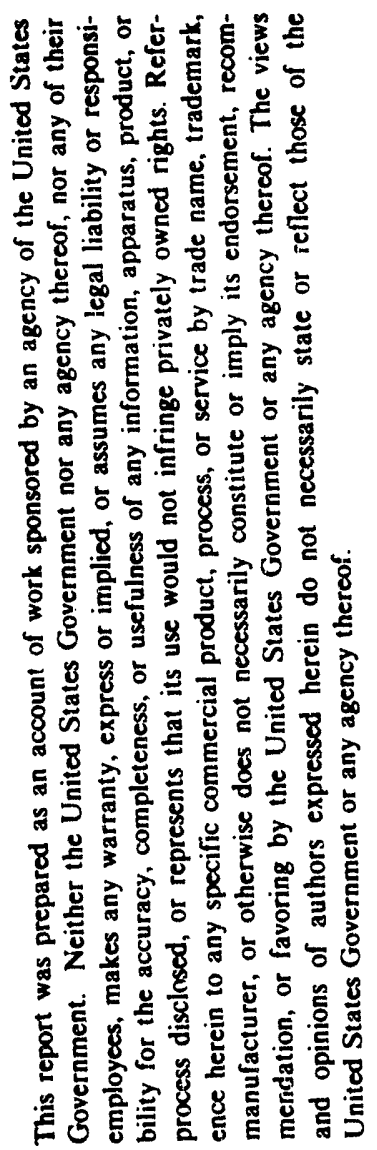

Progress Report for the Period February 28-May 27, 1991

\author{
By \\ Ronald H. Carty \\ Richard A. Knight
}

September 1991

$$
\text { RTCOVED }
$$

FEB 221993

S TI

Work Performed Under Contract No.: DE-AC21-90MC26364

For

U.S. Department of Energy

Office of Fossil Energy

Morgantown Energy Technology Center

P.O. Box 880

Morgantown, West Virginia 26505

By

Institute of Gas Technology

3424 S. State Street

Chicago, Illinois 60616

\section{MASTER}




\section{SUMRARY}

The work performed during the sixth quarterly reporting period (February 28 - May 27, 1991) on the research program, "The MAGSORB Process for Bulk Separation of Carbon Dioxide," is presented in this report. This research program consists of the following eight tasks:

1. Test Plan Preparation

2. Facility Preparation and Equipment Modification

3. Preparation of Sorbent

4. Thermobalance Sorbent Tests

5. Cycle Tests of Sorbent in Packed-Bed Reactor

6. Analysis of Chemical and Physical Properties of Sorbent

7. Test Data Analysis and Interpretation

8. Systems Analysis and Technoeconomic Evaluation

The goal of this study is to investigate the removal of carbon dioxide from a fuel gas produced by a coal gasifier with a $\mathrm{K}_{2} \mathrm{CO}_{3}$-modified $\mathrm{MgO}$ sorbent. The work consists of the measurement of the capacity and rates af absorption of the sorbent as a function of temperature, pressure, and gaseous contaminants. In addition, the effects of repeated absorption and desorption cycling on the physical and chemical properties of the sorbent will be studied.

During the sixth quarter of this program, work continued on the preparation of homogeneous batches of sorbent. It had previously been found that there was not consistent agreement between the $\mathrm{Mg} / \mathrm{K}$ ratios calculated from the amounts of reagents used and the ratios determined by chemical analysis using atomic absorption spectrometry. In our investigation of the causes of these inconsistencies, we also found that there was an unacceptably high variation in the $\mathrm{Mg} / \mathrm{K}$ ratio among the individual sorbent pellets.

This quarter, sorbent pellets that had shown excessive variation in the $\mathrm{Mg} / \mathrm{K}$ ratio were ground and the powder mixed to produce a uniform material. This material was then pelletized with a compaction device and the pellets checked for composition and reactivity. Although this procedure produced pellets with consistent $\mathrm{Mg} / \mathrm{K}$ ratios, thermobalance tests showed reduced 
reactivity. This reduction in reactivity is thought to be due to a reduction in pore size during the pelletization. However, because most of the previous reactivity measurements were conducted with pellets that had a nominal $\mathrm{Mg} / \mathrm{K}$ ratio of 7 rather than 6 which is the value for these pellets, the change in $\mathrm{Mg} / \mathrm{K}$ ratio cannot be ruled out as a possible cause of the reduced reactivity. Next quarter, previously prepared pellets with a nominal $\mathrm{Mg} / \mathrm{K}$ ratio of 7 will be finely ground and the powder mixed prior to pelletizing in a compaction device. Reactivity tests of these pellets should decide whether the $\mathrm{Mg} / \mathrm{K}$ ratio or closing of pores due to the compaction is the cause for the reduced reactivity. If the pellets show closing of pores due to the compaction operation is the cause of the reduced reactivity, pellets will be prepared with a blowing agent such as ammonium carbonate to increase the porosity and increase reactivity. 
TABLE OF CONTENTS

Page

$\begin{array}{lr}\text { INTRODUCTION } & 1\end{array}$

TECHNICAL DISCUSSION

Task 1. Test Plan Preparation 3

Objective 3

Summary 3

Task 2. Facility Preparation and Equipment Modification 3

Objective 3

Summary

Task 3. Preparation of Sorbent Material 3

Objective 3

Summary 4

Plans for Next Quarter 7

Task 4. Thermobalance Sorbent Tests . 7

Objective 7

Summary 7

Plans for Next Quarter $\quad 11$

Task 5. Cycle Tests of Sorbent in Packed-Bed Reactors - 11

Task 6. Analysis of Chemical and Physical Properties of Sorbent 11

Task 7. Test Data Analysis and Interpretation. 11

Task 8. Systems Analysis and Technoeconomic Evaluation 11

Objective 11

Summary 11

LIST OF TABLES

Table $\quad \underline{\text { Page }}$

1 Variation in $\mathrm{Mg} / \mathrm{K}$ Mole Ratio Among Sorbent Batches

\section{LIST OF FIGURES}

Figure

$\underline{\text { Page }}$

$1 \quad \mathrm{CO}_{2}$ Absorption in Thermobalance Test 0214 (Batch 18)

$2 \quad \mathrm{CO}_{2}$ Absorption in Thermobalance Test 0215 (Batch 18)

$3 \quad \mathrm{CO}_{2}$ Absorption in Thermobalance Test 0218 (Batch 19)

$\mathrm{CO}_{2}$ Absorption in Thermobalance Test 0217 (Batch 18)

$\mathrm{CO}_{2}$ Absorption in Thermobalance Test 0219 (Batch 20) 


\section{INTRODUCTION}

Gasification of coal for synthesis gas production yields a mixture of $\mathrm{CO}, \mathrm{CO}_{2}, \mathrm{H}_{2}, \mathrm{H}_{2} \mathrm{O}, \mathrm{H}_{2} \mathrm{~S}$, and $\mathrm{NH}_{3}$. The composition of the resulting gas is adjusted as required for various uses by removing or enhancing the concentration of the various components. For example, the use of the gas for methanol synthesis requires the enhancement of the $\mathrm{H}_{2}$ content with respect to $\mathrm{CO}$, removal of the bulk of the $\mathrm{CO}_{2}$ and $\mathrm{H}_{2} \mathrm{O}$, and complete removal of the $\mathrm{H}_{2} \mathrm{~S}$, This program deals with the bulk separation of carbon dioxide by application of the novel MAGSORB process.

In the MAGSORB process, the $\mathrm{CO}_{2}$ is removed from raw fuel gases by a $\mathrm{MgO} / \mathrm{K}_{2} \mathrm{CO}_{3}$ sorbent at elevated temperature $\left(650^{\circ}\right.$ to $1000^{\circ} \mathrm{F}$ ) and pressure ( 300 to $850 \mathrm{psi}$ ) to match with pressurized coal gasification and high-temperature water-gas shift operations. The $\mathrm{CO}_{2}$ removal is conducted in a swing-bed absorption/desorption cycle in which $\mathrm{MgO}$ absorbs the $\mathrm{CO}_{2}$ and the $\mathrm{MgCO}_{3}$-containing spent sorbent is regenerated either by decreasing the pressure or by elevating the temperature to convert the $\mathrm{MgCO}_{3}$ to $\mathrm{MgO}$ and $\mathrm{CO}_{2}$. The overall objective of this program is to evaluate and develop a hightemperature process for $\mathrm{CO}_{2}$ separation using a $\mathrm{MgO} / \mathrm{K}_{2} \mathrm{CO}_{3}$ sorbent, which has the potential to significantly reduce the capital and operating costs for converting raw fuel gas to synthesis gas.

The specific objectives of this study will address the following topics:

- Preparation of a $\mathrm{CO}_{2}$ sorbent material composed of MgO modified with $\mathrm{K}_{2} \mathrm{CO}_{3}$

- Investigation of the $\mathrm{CO}_{2}$ absorption and desorption rates of the $\mathrm{MgO} / \mathrm{K}_{2} \mathrm{CO}_{3}$ sorbent as a function of the system temperature and pressure

- Determination of the effects of $\mathrm{H}_{2} \mathrm{~S}$ and $\mathrm{NH}_{3}$ on the absorption characteristics of the $\mathrm{MgO} / \mathrm{K}_{2} \mathrm{CO}_{3}$ sorbent

- Testing of the change in absorption and desorption characteristics of the sorbent after 3,7 , and 20 absorption/desorption cycles

- Examination of the chemical and physical changes in the sorbent as a result of the absorption/desorption cycles

- A technoeconomic analysis and comparison of the novel $\mathrm{CO}_{2}$ separation scheme with conventional alternatives, performed in conjunction with Bechtel National, Inc. 
The objectives of the program tasks, their technical progress during the sixth quarter (February 28 through May 27, 1991), and the plans for the next quarter are presented in this report. 


\section{TECHNICAL DISCUSSION}

\section{Task 1. Test Plan Preparation}

\section{Objective}

The objective of this task is to prepare a test plan including a baseline experimental program, chemical and physical analyses, and data and systems analyses to be accomplished in the project, and to define the schedule for performing these tasks.

\section{Summary}

The Test Plan for this project, which details the experiments to be conducted, their rationale, the analyses to be performed, and the handling of the experimental results, was completed and submitted for approval during the first quarter of the program.. The implementation of the Test Plan was begun in January 1990.

\section{Task 2. Facility Preparation and Equipment Modification}

objective

The objective of this task is to modify existing equipment and to fabricate new apparatus to be used in the experimental work. In addition, this task also include the operational shakedown of the apparatus to ensure minimal downtime during the experimental tests. This tash includes operational checks of the thermobalance that will be used in Task 4 and construction of a simple packed-bed reactor for the cycle tests to be performed in Task 5 .

\section{$\underline{\text { Summary }}$}

The construction of the packed-bed reactor was delayed pending solution of the problem of sorbent inhomogeneity.

\section{Task 3. Preparation of Sorbent Material}

Objective

The purpose of this task is to prepare the primary reference sorbent to be tested, as well as compositional variations of this sorbent, and a standard 
sorbent material consisting of unmodified $\mathrm{MgO}$ pellets, to be used for comparison. The sorbents to be used in the experimental tests include the following:

- A MgO standard

- $A \mathrm{~K}_{2} \mathrm{CO}_{3}$-modified $\mathrm{MgO}$ reference sorbent with an approximate $\mathrm{Mg}: \mathrm{K}$ molar ratio of $7 / 1$

- $\mathrm{A} \mathrm{K}_{2} \mathrm{CO}_{3}$-modified $\mathrm{MgO}$ sorbent with an approximate $\mathrm{Mg}: \mathrm{K}$ molar ratio of $6 / 1$

- $\mathrm{A} \mathrm{K}_{2} \mathrm{CO}_{3}$-modified $\mathrm{MgO}$ sorbent with an approximate $\mathrm{Mg}: \mathrm{K}$ molar ratio of $8 / 1$

\section{Summary}

Following preparation of previous batches of sorbent, we found that the $\mathrm{Mg} / \mathrm{K}$ ratios calculated from the amounts of reagents used and the ratios determined by chemical analysis using atomic absorption spectrometry were not consistently in agreement. Analyses of multiple pellets from each batch also revealed a gross inhomogeneity in the material with respect to potassium content. Because of this we have investigated alternative methods of mixing the ingredients to achieve chemical homogeneity at the desired $\mathrm{Mg} / \mathrm{K}$ ratio.

The results of these efforts are summarized in Table 1.

At this point, a determination was made to prepare pellets by crushing, remixing, and repelletizing previously calcined batches, in order to ensure a uniform MAGSORB material for resumed thermobalance testing. A mechanical pelletizing device was used to reconstitute calcined material from batch 16 , which had an average $\mathrm{Mg} / \mathrm{K}$ ratio of 7.2 . Approximately $25 \mathrm{~g}$ of reconstituted material was made in this way, and designated batch 18 . A ten-pellet sample of this batch of sorbent was analyzed and found to be acceptably uniform with respect to $\mathrm{Mg} / \mathrm{K}$ ratio. The $\mathrm{Mg} / \mathrm{K}$ ratio was 6.68 , and the relative standard deviation in $\mathrm{Mg} / \mathrm{K}$ ratio among ten randomly selected pellets was 3.78 . This degree of variation is well within the error limits of the analytical technique. The $\mathrm{CO}_{2}$ content of the batch was $11.1 \%$, which, after accounting for $\mathrm{K}_{2} \mathrm{CO}_{3}$, indicated that about $8 z$ of the magnesium was present as $\mathrm{MgCO}_{3}$. 
Table 1. VARIATION IN MG/K MOLE RATIO AMONG SORBENT BATCHES

\begin{tabular}{|c|c|c|c|c|c|}
\hline \multirow[b]{2}{*}{ Batch } & \multirow[b]{2}{*}{ Comments } & \\
\hline & & Calc & Meas & $\begin{array}{l}\text { Meas/ } \\
\mathrm{Calc} \\
\end{array}$ & $\begin{array}{c}8 \operatorname{Rel} \\
\text { Std Dev } \\
\end{array}$ \\
\hline 13 & $\begin{array}{l}\text { Added powder to } \mathrm{KOH} \text { solu- } \\
\text { tion in homogenizer; } \\
\text { analyzed before calcining }\end{array}$ & 6.0 & 6.6 & 1.1 & 9.7 \\
\hline$"$ & After calcining in air & 6.0 & 9.5 & 1.6 & 27.7 \\
\hline 14 & $\begin{array}{l}\text { Same mixing method as batch } \\
13 \text {, but used more water in } \\
\text { KOH solution for thinner } \\
\text { slurry; before calcining }\end{array}$ & 7.0 & 7.4 & 1.1 & 36.0 \\
\hline$"$ & $\begin{array}{l}\text { After calcining in tube } \\
\text { furnace in } 758 \mathrm{H}_{2} / 258 \mathrm{CO}_{2}\end{array}$ & 7.0 & 9.3 & 1.3 & 21.0 \\
\hline$"$ & After calcining in air & 7.0 & 9.7 & 1.4 & 27.0 \\
\hline 15 & $\begin{array}{l}\text { Same mixing method as } \\
\text { batches } 13 \text { and } 14 \text {, after } \\
\text { thickening paste in vacuum } \\
\text { oven at } 104^{\circ} \mathrm{F}\end{array}$ & 6.0 & 6.8 & 1.1 & NA \\
\hline$"$ & Extruded paste & 6.0 & 8.9 & 1.5 & 21.7 \\
\hline$"$ & $\begin{array}{l}\text { Pellets air-dried over- } \\
\text { night; not calcined }\end{array}$ & 6.0 & 5.7 & 0.95 & 27.9 \\
\hline 16 & $\begin{array}{l}\text { Revised mixing order: } \\
\text { slurry } 4 \mathrm{MgCO}_{3} \cdot \mathrm{Mg}(\mathrm{OH})_{2} \cdot 5 \mathrm{H}_{2} \mathrm{O} \\
\text { in water, then add } \mathrm{KOH} \\
\text { solution; unthickened paste }\end{array}$ & 6.0 & 6.2 & 1.03 & 1.9 \\
\hline " & $\begin{array}{l}\text { After thickening and } \\
\text { extrusion }\end{array}$ & 6.0 & 7.1 & 1.2 & 7.7 \\
\hline$"$ & $\begin{array}{l}\text { After overnight air-drying } \\
\text { of pellets }\end{array}$ & 6.0 & 7.8 & 1.3 & 32.6 \\
\hline$"$ & After calcining in air & 6.0 & 7.2 & 1.2 & 27.8 \\
\hline 17 & $\begin{array}{l}\text { Same mixing method as batch } \\
16 \text {, but used rapid drying } \\
\text { of paste; uncalcined }\end{array}$ & 6.0 & 7.9 & 1.3 & 17.8 \\
\hline$"$ & After calcining in air & 6.0 & 14.5 & 2.4 & 80.5 \\
\hline
\end{tabular}

a Based on analysis of 10 pellets or representative sub-samples 
Table 1., cont. VARIATION IN MG/K MOLE RATIO AMONG SORBENT BATCHES

\begin{tabular}{|c|c|c|c|c|c|}
\hline \multirow{3}{*}{$\frac{\text { Batch }}{18}$} & \multirow[b]{2}{*}{ Comments } & \multicolumn{4}{|c|}{$\mathrm{Mg} / \mathrm{K}$ Ratio } \\
\hline & & $\mathrm{Calc}$ & Meas & $\begin{array}{l}\text { Meas/ } \\
\text { Calc }\end{array}$ & $\begin{array}{c}8 \operatorname{Rel} \\
\text { Std Dev } \\
\end{array}$ \\
\hline & $\begin{array}{l}\text { Calcined pellets from } \\
\text { Batch } 16 \text { were crushed, the } \\
\text { powder blended and pellets } \\
\text { reconstituted in a } \\
\text { compressive pelletizer }\end{array}$ & 6.0 & 6.7 & 1.1 & 3.7 \\
\hline 19 & $\begin{array}{l}\text { Crushed uncalcined pellets } \\
\text { from Batch } 11 \text {, powder } \\
\text { pelletized as for Batch } 18 \\
\text { and then pellets were } \\
\text { calcined }\end{array}$ & 6.0 & 6.6 & 1.1 & 5.7 \\
\hline 20 & $\begin{array}{l}\text { Paste prepared from } \\
\text { reagents, slurry air dried, } \\
\text { ground, and mixed; powder } \\
\text { was rewetted and paste } \\
\text { exrrided into pellets }\end{array}$ & 6.0 & 9.1 & 1.5 & 24.7 \\
\hline
\end{tabular}

a Based on antalysis of 10 pellets or representative sub-samples

To prepare Batch 19, pellets from a previous batch (Batch 11A) which had not yet been calcined were crushed, homogenized, and pelletized in the pellet press used to prepare the previous batch 18 . These pellets were then calcined in an oven at $900^{\circ} \mathrm{F}$. It was felt that this procedure would result in a more open pore structure than the technique used for batch 18 , in which pellets were made from previously calcined material. Ten batch 19 pellets were randomly selected and analyzed, showing an average $\mathrm{Mg} / \mathrm{K}$ mole ratio of 6.64 with a relative standard deviation of 5.78 . This confirmed acceptable uniformity of composition for the batch.

To prepare more reactive but uniform composition pellets, a new MAGSORB (Batch 20) was prepared from reagents and dried in air. The dry cake was then ground, and the fine powder mixed to increase uniformity. However, instead of pelletizing the dried powder in a pellet press, the fine powder was rewetted and the paste extruded into pellets similar to the technique used for the original pellets. This method of preparation did not increase the reac ivity 
of carbon dioxide absorption, and the composition of the ten-pellet sample showed an average $\mathrm{Mg} / \mathrm{K}$ ratio of 9.1 with a standard deviation of 24.78 .

\section{Plans for Next Quarter}

Prepare batches of sorbent by: grinding previously prepared pellets to produce a uniform composition powder, pelletizing this material (with and without a blowing agent such as ammonium carbonate) using a compaction pelletizing device, and calcining the resultant pellets slowly in air.

\section{Task 4. Thermobalance Sorbent Tests \\ Objective}

The objectives of this task are to determine the operating conditions of temperature and pressure to be used in the absorption and desorption of $\mathrm{CO}_{2}$ by the sorbent and to investigate the effect of variation of the $\mathrm{K}_{2} \mathrm{CO}_{3}$ content of the MgO sorbent. Once the operating conditions and sorbent composition are fixed, the rates of absorption and desorption will be determined. All of the tests in this task are conducted in a high-pressure thermobalance.

\section{Summary}

Five thermobalance tests were performed during the quarter. Three were conducted using the Batch 18 pellets. Figures 1-3 show the weight gain-vstime plots for these tests. All of the tests were conducted on the absorption cycle at $800^{\circ} \mathrm{F}$ and 300 psig using a gas atmosphere of $41.58 \mathrm{CO}_{2} / 41.58 \mathrm{He} / 178$ steam. Test 0214 resulted in a 398 weight gain over 32.3 minutes, which represented 598 of the theoretical limiting weight gain. Test 0215 was a duplicate of Test 0214 , and showed a similar weight gain of 378 absolute, or 568 of the theoretical limit, but at a 508 slower rate. The rate of weight gain in both of these tests was low compared with previous tests using MAGSORB prepared from extruded slurry batches with a $7: 1 \mathrm{Mg}$-to-K ratio. In order to determine whether this may have been due to decreased surface porosity caused by compressive pelletization, Test 0217 was made with batch 18 pellets broken into pieces approximately the size of the original pellets to increase surface area and expose fresh surface. However, the results of Test 0217 actually showed further decreased reactivity, with a weight gain of only about 228 in 


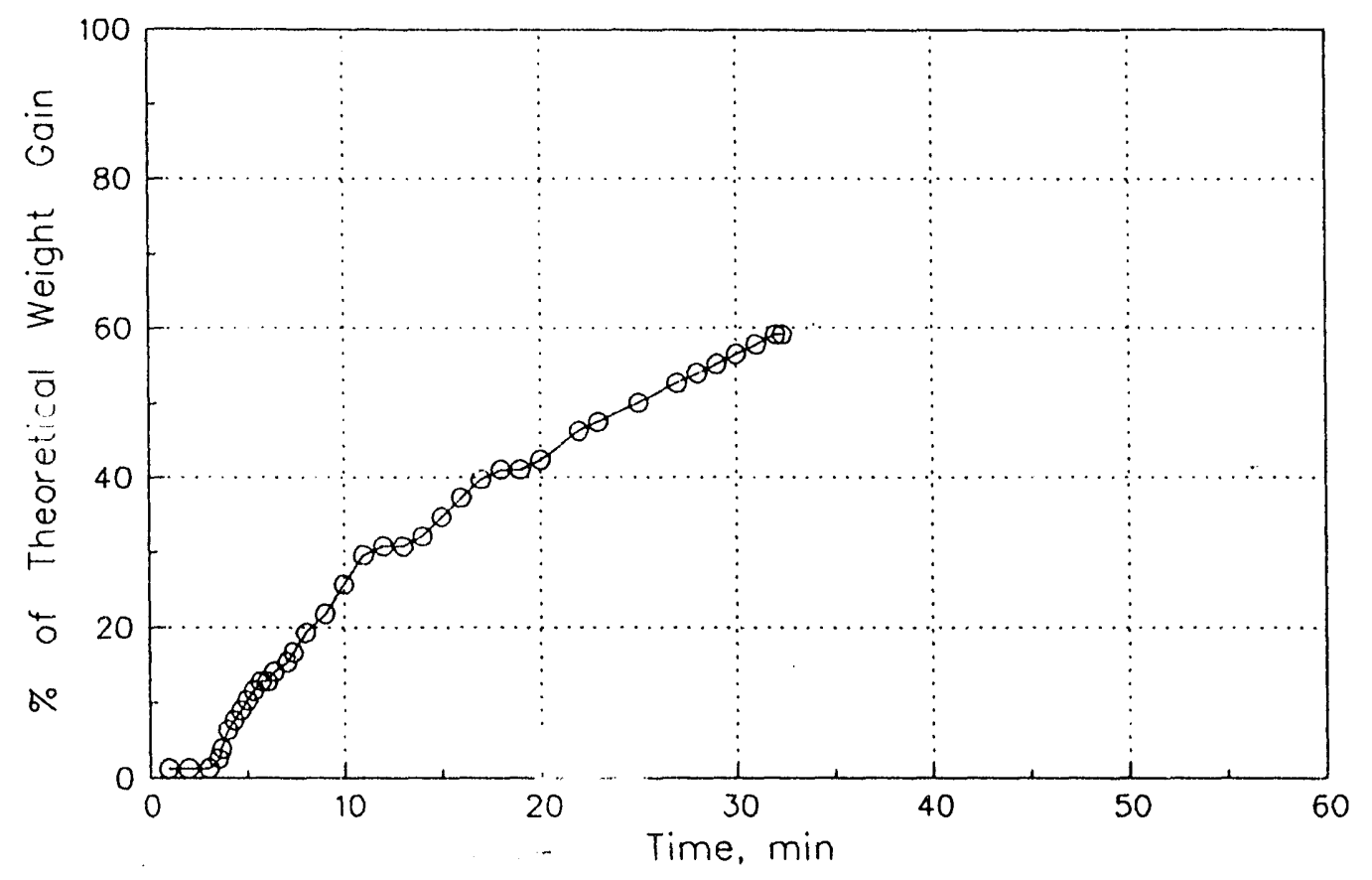

Figure 1. $\mathrm{CO}_{2}$ ABSORPTION IN THERMOBALANCE TEST 0214 (BATCH 18)

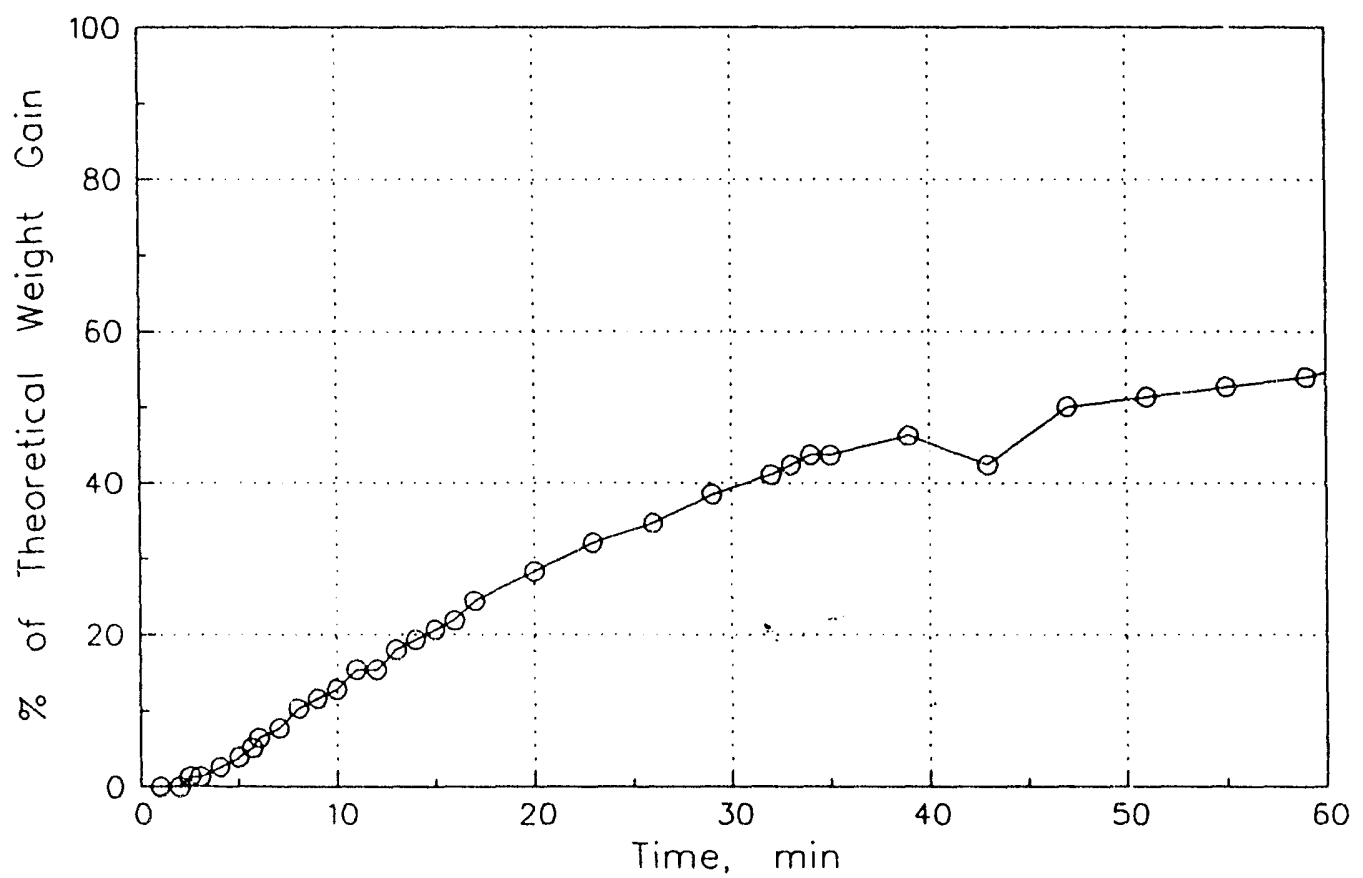

Figure 2. $\mathrm{CO}_{2}$ ABSORPTION IN THERMOBALANCE TEST 0215 (BATCH 18) 


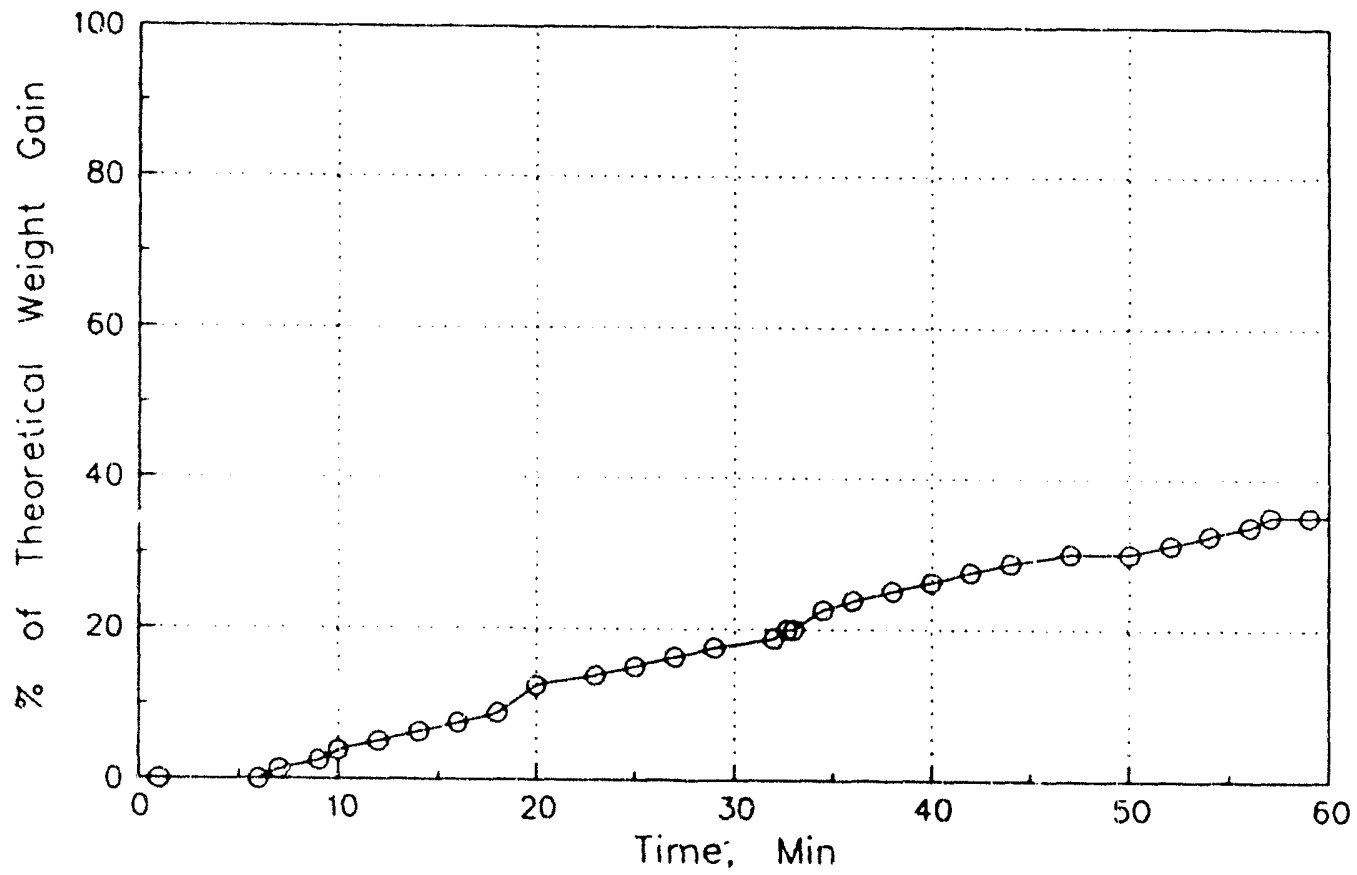

Figure 3. $\mathrm{CO}_{2}$ ABSORPTION IN THERMOBALANCE TEST 0218 (BATCH 19)

30 minutes, as shown in Figure 3. The reason for this diterioration of reactivity is not clear.

One thermobalance adsorption test (Test 0218) was conducted with Batch 19, which resulted in the weight gain-vs-time curve shown in Figure 4. The test conditions were $508 \mathrm{CO}_{2} / \mathrm{He}$ at $800^{\circ} \mathrm{F}$ and $300 \mathrm{psig}$. The results indicate that the low reactivity which was previously observed for Batch 18 is also characteristic of Batch 19. It appears that the crushing and repelletizing method, while preserving the uniform composition of the pellets, may destroy the reactivity of the MAGSORB. The compression of the material may be collapsing the pore structure and inhibiting the access of reactants to the inside of the pellet.

One thermobalance adsorption test (Test 0218) was conducted with Batch 20, which resulted in the weight gain-vs-time curve shown in Figure 5 . The test conditions were $508 \mathrm{CO}_{2} / \mathrm{He}$ at $800^{\circ} \mathrm{F}$ and $300 \mathrm{psig}$. The results indicate a reactivity similar to that previously observed for Batch 18 , higher than that of Batch 19 but much lower than that of earlier batches such as Batches 1 and 2. The common factor in Batches $18-20$ is the $\mathrm{Mg} / \mathrm{K}$ ratio of $6: 1$, 


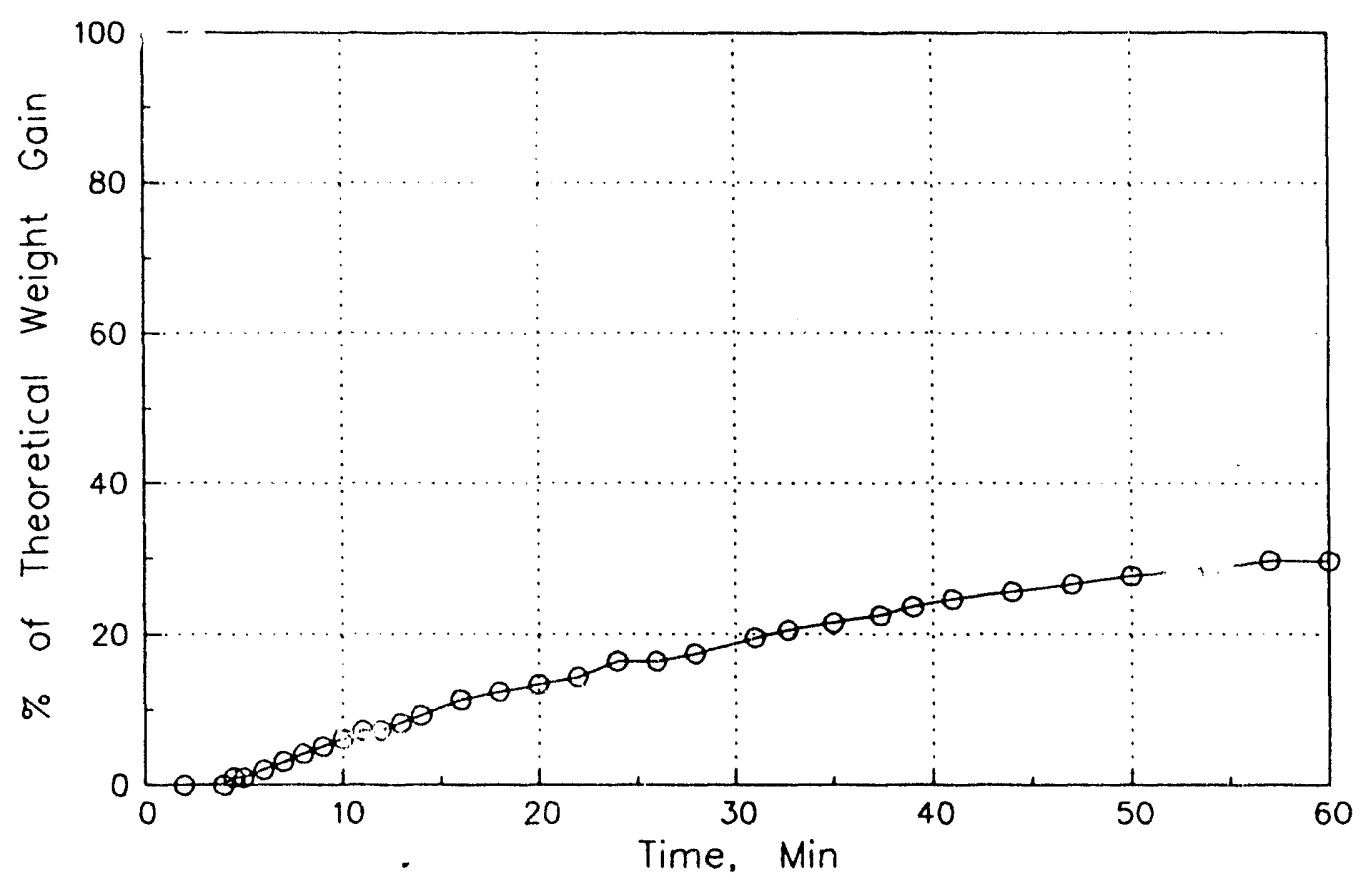

Figure 4. $\mathrm{CO}_{2}$ ABSORPTION IN THERMOBALANCE TFST 0217 (BATCH 18)

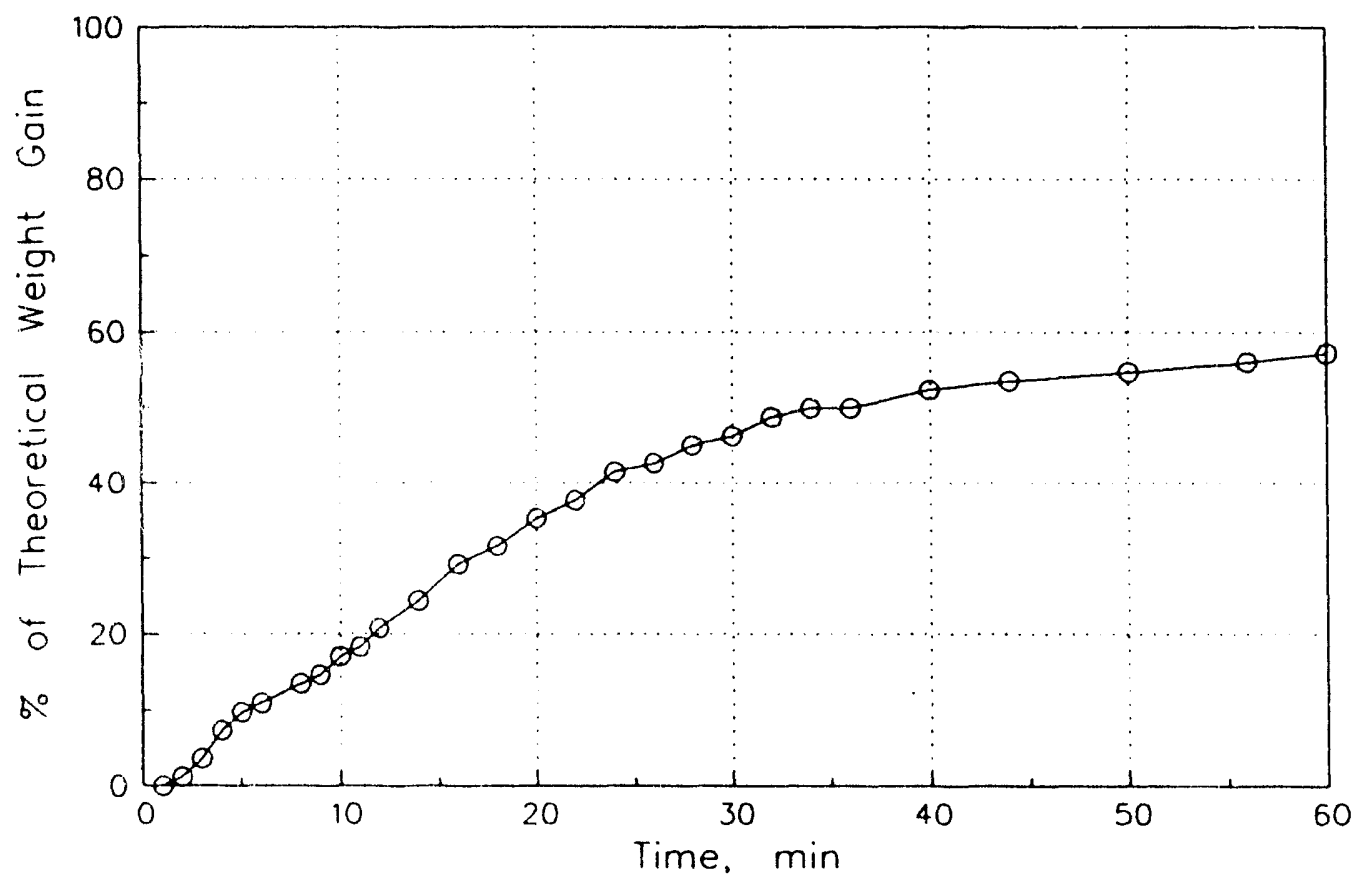

Figure 5. $\mathrm{CO}_{2}$ ABSORPTION IN THERMOBALANCE TEST 0219 (BATCH 20) 
and the results indicate that the $\mathrm{Mg} / \mathrm{K}$ ratio, rather than the method of pelletization, may be the cause in the decrease in reactivity and capacity.

Plans for Next Quarter

bonduct thermobalance tests to determine the cause of reduced reastivity.

Task 5. Cycle Tests of Sorbent in Packed-Bed Reactors

No work was scheduled for this task during the quarter.

Task 6. Analysis of Chemical and Physical Properties of Sorbent

The only analyses performed this quarter were the magnesium and potassium contents of the modified sorbents. These results are reported in connection with the results of the testing of these sorbents.

\section{Task 7. Test Data Analysis and Interpretation}

The analysis and interpretation of the data obtained this quarter have been included in the discussion of the tasks in which the data were collected.

\section{Task 8. Systems Analysis and Technoeconomic Evaluation}

\section{Objective}

The objective of this task is to develop an optimum scheme for integrating the MAGSORB Process for $\mathrm{CO}_{2}$ absorption with selected gasification and gas-upgrading processes for a technoeconomic analysis and comparison with conventional alternatives. In particular, this will entail a comparison of the estimated economics of the MAGSORB process with removal of $\mathrm{CO}_{2}$ by conventional Rectisol technology using refrigerated methanol scrubbing, in the production of a synthesis gas for methanol production.

\section{Summary}

No work was scheduled on this task for this quarter. 

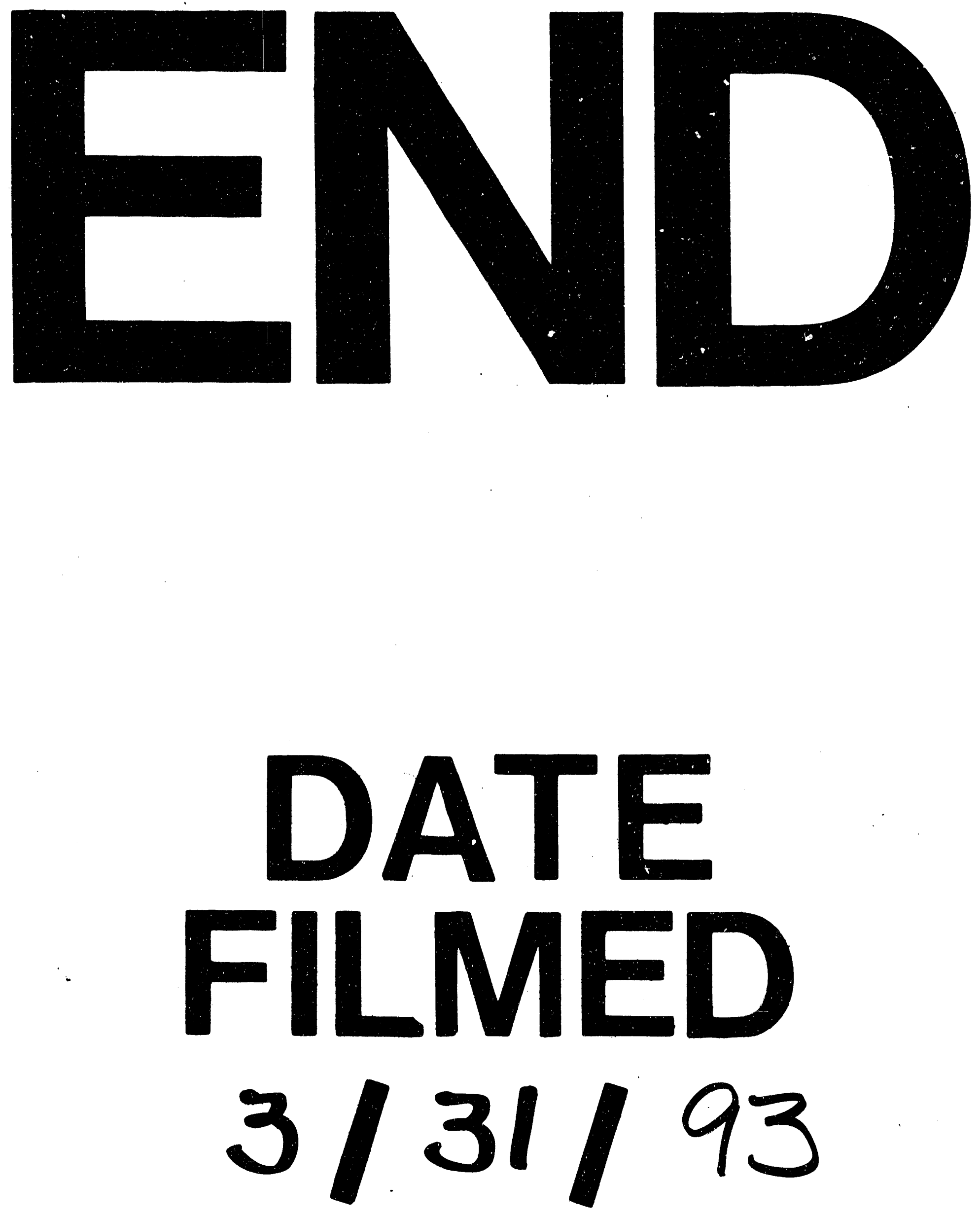

I 
